\title{
The role of deep flaming in violent pyroconvection
}

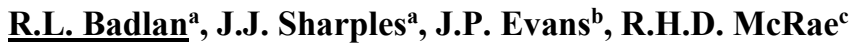 \\ ${ }^{a}$ Applied and Industrial Mathematics Research Group, School of Physical, Environmental and Mathematical \\ Sciences, UNSW Canberra, Australia. \\ ${ }^{b}$ Climate Change Research Centre, Faculty of Science, University of New South Wales, Sydney, Australia \\ ${ }^{c}$ Australian Capital Territory Emergency Services Agency, Canberra, Australia \\ Email: r.badlan@adfa.edu.au
}

\begin{abstract}
Violent fire-driven convection can manifest as towering cumulus or cumulonimbus clouds, the latter of which are known as firestorms (pyroCb). These extreme fires can have devastating impacts on environment and society, and appear to be a worsening problem. The major concerns surrounding these large pyroconvective events are that their associated fire spread is highly unpredictable and that they're generally not suppressible. Indeed, current methods of fire spread prediction, including the use of empirical and semiempirical modelling approaches, fall short when attempting to predict fire behaviour associated with these events. In particular, they commonly under-predict the rate of spread in such situations, when broader-scale fire-atmosphere interactions are dominant. To date, research into large pyroconvective events has either focused on the processes involved in normal atmospheric convection, or on surface fire weather and associated fuel conditions. While some investigations have combined the two approaches, a definitive study into both the effects of the surface conditions and the fire-atmosphere interactions is still needed to better understand their respective role in the development of extreme fires.
\end{abstract}

This paper incorporates recent insights into dynamic fire propagation into a coupled fire-atmosphere fire modelling framework to test the combined effects of fire behaviour and atmospheric structure on the occurrence of violent pyroconvective events. In particular, we consider the role of factors such as the spatial expanse and intensity of the fire, and the stability of the atmosphere (both in terms of temperature lapse and moisture profile). The effects of these variables on extreme pyroconvective development are investigated in a systematic way, varying these parameters using the coupled fire-atmosphere WRF-Fire (Weather Research and Forecasting Model (WRF)). In the initial work presented in this paper we focus on the case where the fire is represented by a static heat source of variable dimension and intensity.

Analyses were conducted to investigate how (a) the size of the fire (i.e. area of deep flaming) and (b) the intensity of the sensible heat source affects the plume development. Results from preliminary analyses of dry, static fires indicated that the areal expanse of the fire strongly influences the development of the column of deep convection associated with violent pyroconvective events. This supports the hypothesis that plumes above zones of deep flaming are less influenced by entrainment than plumes emanating from typical linear fire fronts. While air is entrained at the plume boundary, the inner core of the plume is less able to entrain air. As a consequence, the areal nature of the heat source driving convection has an influence on the dynamics of the plume - in particular, the heights it can attain. The magnitude of the heat flux produced by the fire is also important for areas of deep flaming up to a minimum of $2 \mathrm{~km}$ diameter, but as the size of the heat source increases beyond a $2 \mathrm{~km}$ diameter, this appears to be less influential on the way the plume develops.

Our findings provide motivation for further investigation into the effect of the fire's attributes on the immediate atmosphere. They also have the potential to significantly improve forecasting of blow up fire events. Indeed, by combining our findings with recent insights into dynamic fire propagation and improved operational information relating to the atmospheric profile (e.g. through enhanced capability to conduct atmospheric soundings) it is feasible to provide fire agency personnel with far more targeted methods and tools that can be used to better distinguish fires that are likely to develop into violent pyroconvective events.

Keywords: Wildfire simulation, fire-atmosphere interaction, deep flaming, pyroconvection 


\section{INTRODUCTION}

Extreme wildfires occur throughout the world and are the most severe category of bushfire (Sharples, et al. 2016). Violent pyroconvective events; that is, towering pyrocumulus (pyroCu) and pyrocumulonimbus (pyroCb) impact the surface as well as extending their influence into the atmosphere. Extreme wildfires have a large cost to society through the destruction of buildings and loss of lives, as well as forestry and agricultural productivity and sites of cultural importance (Sharples et al. 2016). The 2009 Black Saturday fires in Victoria, for example, resulted in the loss of 173 lives and a total economic cost estimated at $\$ 4.4$ billion (Teague, et al. 2010). Population growth is also causing expansion of urban areas and increasing the proportion of the urban margins with the surrounding woodland and forested neighbouring areas. These demographic changes combined with the increased likelihood of extreme wildfires under climate change, mean that the risk of extreme wildfires to the community will increase. It is therefore important to improve our understanding of the drivers of these catastrophic events, and to use that understanding to devise better ways of predicting their occurrence and to inform better management options that might ameliorate the risk.

These extreme fires manifest as coupled fire-atmosphere events, which can have a significant effect on local weather patterns. Entrainment into the plume of a violent pyroconvective event can result in highly erratic and turbulent winds in the vicinity of the fire, while within the fire's convective plume, organised flows can be produced - possibly resulting in downbursts, which are problematic to firefighters and planners. Furthermore, the effect of smoke shading can result in thermal gradients over the land surface, which can produce buoyancy flows whose influence can extend some distance away from the fire (Clements, et al. 2007). The development of a deep convective column into a pyroCb may also transport smoke into the lower stratosphere as the enhanced plume overshoots the troposphere, thereby depositing aerosols (e.g. smoke and ash) high in to the atmosphere where it can then be transported around the globe (Fromm, et al. 2010). Injection of aerosols into the atmosphere leads to extended lifetime of convective clouds (Lindsey and Fromm 2008) as well as the pollution of the stratosphere (Fromm, et al. 2005, Fromm, et al. 2008, Fromm, et al. 2008), with broader climatic consequences.

PyroCbs often produce lightning, which may result in the ignition of additional fires and even spawn tornadoes (Fromm, et al. 2006, McRae, et al. 2013), both of which were observed in the 2003 Canberra fires. The spot fires produced by lightning strikes (and/or from embers) may coalesce into a larger fire, which due to the nature of its formation exhibits sustained and intense flaming over a large spatial expanse. We refer to these instances as instances of 'deep flaming' (McRae, et al. 2015). Thus, deep flaming describes large areas of the landscape affected by quasi-simultaneous active flaming. Deep flaming events result in large spatial integrals of instantaneous energy release, and should be considered as quite distinct from the more typical frontal propagation of a wildfire, which has a more linear structure. Deep flaming events can encompass several square kilometres, and can arise in a number of ways, for example:

- Very strong winds - so the head fire advances more rapidly than the back of the flaming zone;

- Change in wind direction - so the long flank of a fire is transformed into a fast running head fire;

- Eruptive fire behaviour - where steep slopes can cause a fire to accelerate rapidly;

- Vorticity-driven lateral spread - where strong winds and steep terrain interact to rapidly drive a fire laterally, accompanied by downwind spotting (Sharples, et al. 2012, Simpson, et al. 2013, Simpson, et al. 2014); and

- $\quad$ Fire coalescence - including mass spot fires from embers and lightning or merging of fires introduced into the landscape by other means such as back-burning.

Deep flaming has also shown itself to be a characteristic of violent pyroconvective events and is conducive to the development of deep convection, as seen in the 2003 Canberra fires, the 2014 Grampian fires in Victoria and more recently, the Sir Ivan fire that destroyed Uarbry, NSW in February this year. McRae et al. (2015) demonstrated a spatiotemporal link between deep flaming events, as identified in multispectral linescans of the fire, with radar echotop maxima and the strongest radar returns. As entrainment of environmental air occurs along the perimeter of the plume, it is hypothesised that the larger and more regular-shaped the fire area, the less mixing of hot air will occur away from the plume boundary, enabling the plume to reach an adequate height for the latent heat release and atmospheric instability to further influence the convection (Finney and McAllister 2011). Therefore, further research into how deep flaming may influence pyroconvection is necessary for better prediction of such events and will increase our understanding of fireatmosphere interactions more generally.

A number of models have investigated the interactions of atmosphere and fire and also note how pyrogenic moisture release plays a role in pyroconvection (Potter 2005, Cunningham and Reeder 2009, Luderer, et al. 2009, Thurston, et al. 2015, Thurston, et al. 2016). The role of released moisture is an active area of research 
with its relative contribution to pyroconvection still being debated. Although, it is acknowledged that moisture is a vital component of the fluxes released from the fire to the atmosphere, this work initially focuses on the effect of a static heat source only. The model used for this stage of research has no pyrogenic moisture (i.e. fuel or combustion moisture) to allow only the effects of the sensible heat from the fire the convective plume to be determined. The role of moisture will be considered in later stages of research.
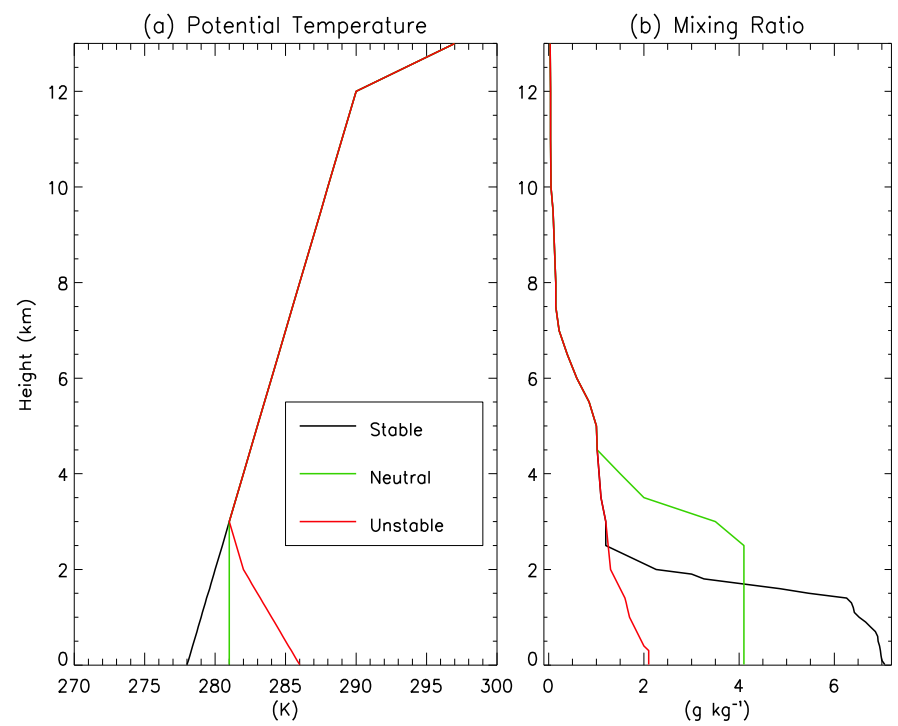

Figure 1. Profiles of (a) potential temperature (K) and (b) mixing ratio $\left(\mathrm{g} \mathrm{kg}^{-1}\right)$ for the lower $15 \mathrm{~km}$ of the atmosphere.

\section{METHOD}

The numerical simulations were performed using version 3.9 of the Weather Research and Forecasting model (WRF) (Skamarock, et al. 2008). This is coupled to the WRF-Fire module (Coen, et al. 2013) and is run in large-eddy simulation (LES) (Moeng, et al. 2007). This configuration explicitly resolves the atmospheric large-scale eddies whereas the small-scale (subgrid) eddies are modelled using a subfilter-scale stress model. The WRF model is fully compressible and utilises a mass-based terrain-following coordinate system.

The computational domain extends $21 \mathrm{~km}$ in both directions horizontally and $30 \mathrm{~km}$ vertically, with vertical and horizontal resolution of $150 \mathrm{~m}$. The WRF-Fire model grid is set to a 4:1 resolution of the atmospheric model grid and therefore the fire model is run with $37.5 \mathrm{~m}$ horizontal resolution. The effects of subgrid turbulence are parameterised using a predictive 1.5-order turbulence kinetic energy closure. A Rayleigh damping layer is used in the top $5 \mathrm{~km}$. The simulations are idealised and have no radiation, physics, planetary boundary layer, or cumulus parameterisation schemes. The microphysics scheme employed is the Single Moment 6-class (WSM6) scheme (Hong and Lim 2006) which is a graupel scheme with ice, snow and graupel processes. It has six categories of hydrometeor, can simulate the process of water vapour, cloud water, cloud ice rain, snow, and graupel, and is particularly suitable for high resolution simulations. There is no terrain in the model and no background wind. The timestep is $0.9 \mathrm{~s}$ for the three smallest fires and $0.3 \mathrm{~s}$ for the largest fire. The lateral boundaries are open and the simulation runs for 6 hours and 30 minutes, with the first 4 hours used for spin-up.

Three different fire intensities are investigated $\left(25 \mathrm{~kW} \mathrm{~m}^{-2}, 50 \mathrm{~kW} \mathrm{~m}^{-2}\right.$, and $\left.100 \mathrm{~kW} \mathrm{~m}^{-2}\right)$ to determine how the sensible heat from the fire may affect the nature of the resulting plume generated by pyroconvection. When evaluating the pyroconvective potential of the fire, the plume height is observed. The heat flux is introduced after boundary layer initialised (i.e., after 4 hours) and is increased linearly over 10 minutes to avoid instability. The spatial extent of the fire source is varied to represent different sizes of deep flaming. Four circular fires are compared each with the following radius: $150 \mathrm{~m}, 500 \mathrm{~m}, 1 \mathrm{~km}$, and $4 \mathrm{~km}$. These fires are run to determine whether the areal extent of a zone of deep flaming affects the generation of violent pyroconvection associated with extreme fires.

The sensitivity of the plume to the horizontal resolution of the grid points is evaluated by producing three simulations with a horizontal resolution of $50 \mathrm{~m}, 100 \mathrm{~m}$ and $150 \mathrm{~m}$ (not shown). There is very little difference between the plumes produced so for the sake of computational resources, the $150 \mathrm{~m}$ horizontal resolution model was used. 
The model is initialized with three different soundings, each representing stable, neutral and unstable atmospheric profiles in the lowest $3 \mathrm{~km}$ of the atmosphere (Fig. 1) and a tropopause located at a height of $12 \mathrm{~km}$. The c-Haines value for each sounding was calculated and produced values of $0.5,6.1$, and 9.5 respectively.

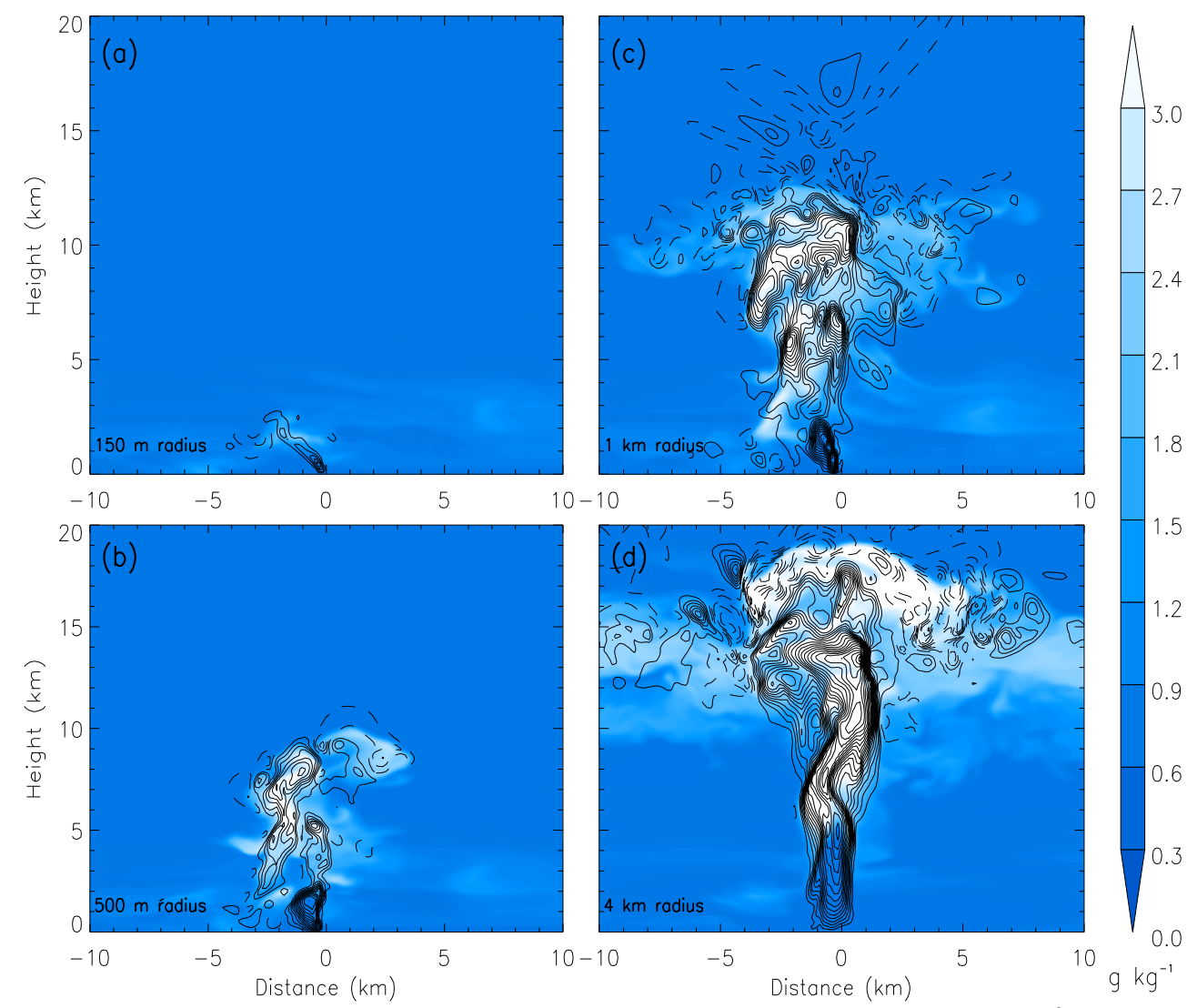

Figure 2. Four vertical cross-sections through the plume after 40 minutes for $100 \mathrm{~kW} \mathrm{~m}^{-2}$ fires with neutral stability. The fires are circular and have radii of $150 \mathrm{~m}$ (top left), $500 \mathrm{~m}$ (below left), $1 \mathrm{~km}$ (top right), and

$4 \mathrm{~km}$ (below right). The coloured contours show the cloud mixing ratio (in $\mathrm{g} \mathrm{kg}^{-1}$ ) and the line contours represent vertical velocity with solid lines representing positive values and dashed lines, negative for every $2 \mathrm{~m} \mathrm{~s}^{-1}$ for (a)-(c) and $8 \mathrm{~m} \mathrm{~s}^{-1}$ for (d).

\section{RESULTS}

\subsection{Effect of fire size on plume}

Figure 2 shows a vertical cross-section through the centre of the domain for each size of fire each with the strongest heat flux of $100 \mathrm{~kW} \mathrm{~m}^{-2}$, with neutral stability, after 40 minutes. It is evident from that the $150 \mathrm{~m}$ radius fire (Fig. 2(a)) that, although it produces a small cloud, does not develop sufficiently to generate any organisation. The $500 \mathrm{~m}$ fire begins to show a substantial core (Fig. 2(b)) and continues to develop organised circulations, maintaining its structure for at least 2 and a half hours. The plume attains a height around $9-$ $10 \mathrm{~km}$ not quite reaching the stratosphere at any time during the simulation. The $1 \mathrm{~km}$ and $4 \mathrm{~km}$ fires both develop into pyroCbs, which are long-lived and attain plume tops of at least $13 \mathrm{~km}$ with strong vertical motion within the convective core. The $4 \mathrm{~km}$ model is producing overly strong vertical velocity as the plume top reaches a height of approximately $19 \mathrm{~km}$ (far into the stratosphere); this may be due to the $100 \mathrm{~kW} \mathrm{~m}^{-2}$ constant heat flux across the fire area, which is at the limit of heat fluxes that may be introduced to the model. However, the different fire sizes illustrate the fact that larger fires are conducive to violent pyroconvection.

\subsection{Effect of fire intensity}

The $1 \mathrm{~km}$ radius fire was then rerun with a constant heat across the fire area of $25 \mathrm{~kW} \mathrm{~m}^{-2}$ and $50 \mathrm{~kW} \mathrm{~m}^{-2}$. Figure 3 shows the same vertical cross- sections previously. Comparing the $100 \mathrm{~kW} \mathrm{~m}^{-2}$ fire in Fig. 2(c) with 
Fig. 3, it is evident that for fires of this size, the fire intensity is influential on the strength of the convection, with a higher intensity fire producing a deeper convective column and a higher cloud top. The $25 \mathrm{~kW} \mathrm{~m}^{-2}$ fire produces a weak plume, but the convection only organises into deep convection with a $50 \mathrm{~kW} \mathrm{~m}^{-2}$ heat source for a fire with $1 \mathrm{~km}$ radius. The $100 \mathrm{~kW} \mathrm{~m}^{-2}$ fire (Fig. 2(c)) develops the strongest pyroconvective cloud and also generates more turbulence due to the increased vertical motion. However, for larger fires $(\sim$ $4 \mathrm{~km}$ radius), it is likely that the intensity of the heat source is of less importance, due to the entrainment of the cooler ambient air, which would not affect the plume to the same extent, with the pyrogenic heat dominating the background atmospheric stability.
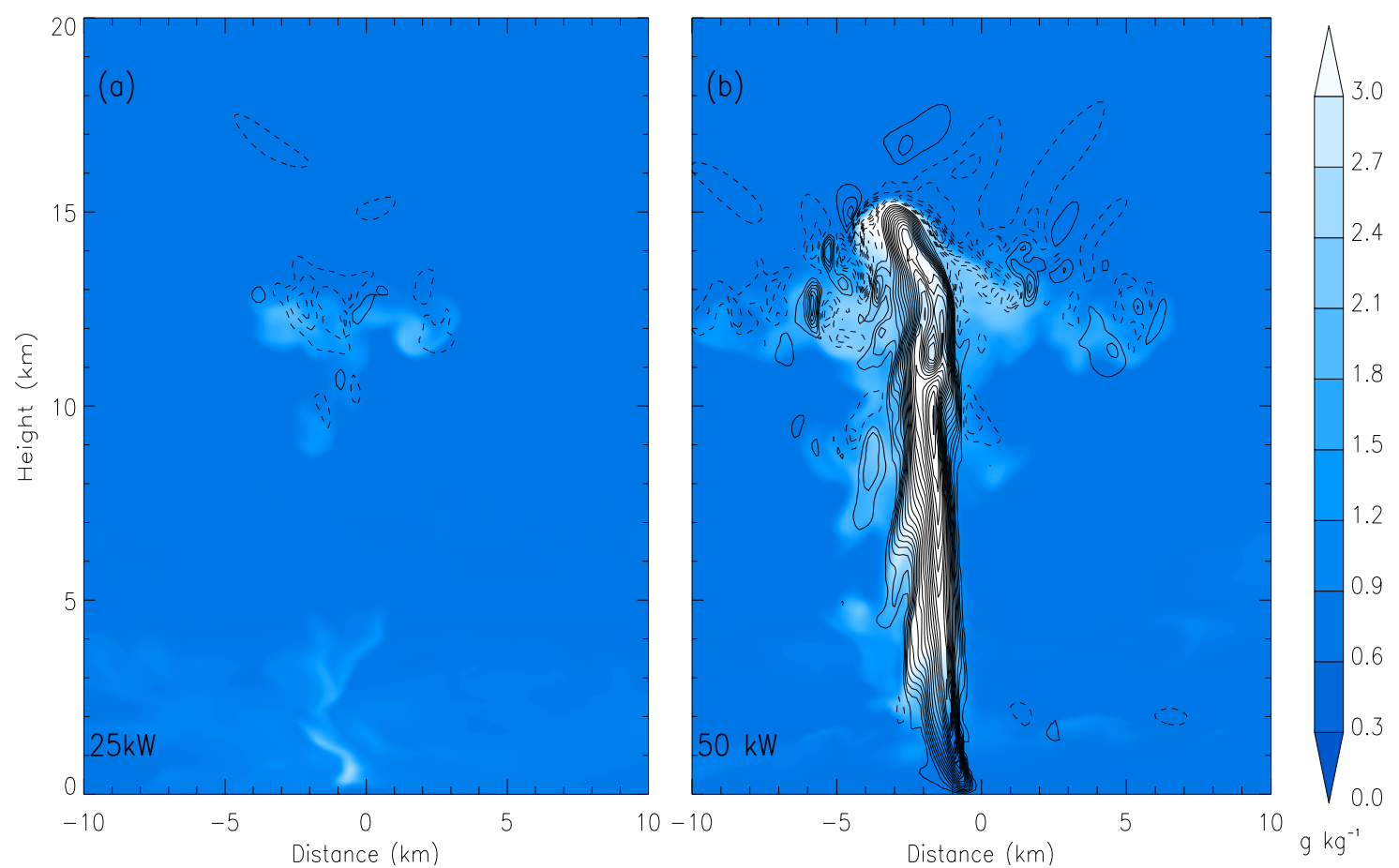

Figure 3. Vertical cross-section through the centre of the plume after 40 minutes, for a $1 \mathrm{~km}$ radius fire in a neutral stability atmospheric environment, for $25 \mathrm{~kW} \mathrm{~m}^{-2}$ fire source (top) and $50 \mathrm{~kW} \mathrm{~m}^{-2}$ (below). The coloured contours show the cloud mixing ratio (in $\mathrm{g} \mathrm{kg}^{-1}$ ) and the line contours represent vertical velocity with solid lines representing positive values and dashed lines, negative for every $2 \mathrm{~m} \mathrm{~s}^{-1}$ for (a)-(c) and $8 \mathrm{~m} \mathrm{~s}^{-1}$ for $(\mathrm{d})$.

\section{DISCUSSION AND CONCLUSION}

Understanding the role that wildfire dynamics and the spatial expanse of a fire's flaming zone have on the development of towering pyrocumulus and/or pyrocumulonimbus has a number of important implications for fire management. Better prediction of the burning characteristics of a fire, which may sometimes be dominated by dynamic modes of fire propagation and a transition to deep flaming, combined with information on the vertical atmosphere will assist fire managers to monitor fires in the landscape and better assess their likelihood of developing into large firestorms.

The 2017 Sir Ivan fire near Dunedoo, NSW, is a case in point. This fire developed into a large pyroCb under the influence of strong prefrontal winds and the enhanced atmospheric instability associated with a trough line. The same broad scale meteorological features were experienced over a broad area, yet the White Cedar fire, only approximately $50 \mathrm{~km}$ to the south east of the Sir Ivan fire, did not develop into a pyroCb. It is hoped that the research presented above, and extensions thereof, can be used to develop an additional level of 'fire triage' that will enable fire agency personnel to better distinguish the likelihood of fires like Sir Ivan and White Cedar developing into large pyroconvective events, or not.

Preliminary analyses of dry, static fires indicated that the areal expanse of the fire strongly influences the development of the column of deep convection associated with violent pyroconvective events. This supports the hypothesis that plumes above zones of deep flaming are less influenced by entrainment than plumes emanating from typical linear fire fronts. The areal nature of the heat source driving convection has an influence on the dynamics of the plume - in particular, the heights it can attain. The magnitude of the heat 
flux produced by the fire is also important for areas of deep flaming up to a minimum of $2 \mathrm{~km}$ diameter, but as the size of the heat source increases beyond a $2 \mathrm{~km}$ diameter, this appears to be less influential on the way the plume develops. These results also suggest that care should be taken when choosing a heat source for idealised models, as the model can be sensitive to the magnitude of the heat flux and may not produce realistic pyroconvection. The largest fire (4 km radius) also produces strong upward motion within the column and this results in an overly high plume top. These simplified idealised simulations nevertheless, give an insight into the relationship between the spatial expanse of a fire's flaming region and the height of the plume, and these insights will be informative to improving forecasting of blow up events.

Further work will extend this research by considering the contribution of pyrogenic moisture fluxes (fuel and combustion moisture) in the development of violent pyroconvection. Further work will also seek to understand the interaction between deep flaming and atmospheric stability by considering other idealized atmospheric profiles (stable and unstable) and atmospheric profiles similar to those observed on days when extreme fire development has taken place. We also note that the results presented here were derived from circular heat sources, which is not the shape a wildfire usually assumes. As such, the effect of the shape of the flaming zone on plume development will also be an interesting avenue of research to pursue.

\section{ACKNOWLEDGMENTS}

This research was funded under the Australian Research Council's Discovery Indigenous Scheme (IN160100029), and undertaken with the assistance of resources provided by the NCI National Facility at the Australian National University through the National Computational Merit Allocation Scheme supported by the Australian Government. The authors are grateful to Philip Cunningham and Janice Coen for helpful discussions.

\section{REFERENCES}

Clements, C. B., R. Perna, M. Jang, D. Lee, M. Patel, S. Street, S. Zhong, S. Goodrick, J. Li and B. E. Potter (2007). Observing the dynamics of wildland grass fires: Fireflux —a field validation experiment. Bulletin of the American Meteorological Society 88(9): 1369-1382.

Coen, J. L., M. Cameron, J. Michalakes, E. G. Patton, P. J. Riggan and K. M. Yedinak (2013). WRF-Fire: coupled weather-wildland fire modeling with the weather research and forecasting model. Journal of Applied Meteorology and Climatology 52(1): 16-38.

Cunningham, P. and M. J. Reeder (2009). Severe convective storms initiated by intense wildfires: Numerical simulations of pyro-convection and pyro-tornadogenesis. Geophysical Research Letters 36(12): n/a-n/a.

Finney, M. A. and S. S. McAllister (2011). A Review of Fire Interactions and Mass Fires. Journal of Combustion 2011.

Fromm, M., R. Bevilacqua, R. Servranckx, J. Rosen, J. P. Thayer, J. Herman and D. Larko (2005). Pyrocumulonimbus injection of smoke to the stratosphere: Observations and impact of a super blowup in northwestern Canada on 3-4 August 1998. Journal of Geophysical Research: Atmospheres 110(D8): 1-16.

Fromm, M., D. T. Lindsey, R. Servranckx, G. Yue, T. Trickl, R. Sica, P. Doucet and S. Godin-Beekmann (2010). The Untold Story of Pyrocumulonimbus. Bulletin of the American Meteorological Society 91(9): 1193-1209.

Fromm, M., E. P. Shettle, K. H. Fricke, C. Ritter, T. Trickl, H. Giehl, M. Gerding, J. E. Barnes, M. O'Neill, S. T. Massie, U. Blum, I. S. McDermid, T. Leblanc and T. Deshler (2008). Stratospheric impact of the Chisholm pyrocumulonimbus eruption: 2. Vertical profile perspective. Journal of Geophysical Research: Atmospheres 113(D8): 1-16.

Fromm, M., O. Torres, D. Diner, D. Lindsey, B. Vant Hull, R. Servranckx, E. P. Shettle and Z. Li (2008). Stratospheric impact of the Chisholm pyrocumulonimbus eruption: 1. Earth-viewing satellite perspective. Journal of Geophysical Research: Atmospheres 113(D8): 1-16.

Fromm, M., A. Tupper, D. Rosenfeld, R. Servranckx and R. McRae (2006). Violent pyro-convective storm devastates Australia's capital and pollutes the stratosphere. Geophysical Research Letters 33(5): 1-5.

Hong, S.-Y. and J.-O. J. Lim (2006). The WRF single-moment 6-class microphysics scheme (WSM6). Journal of the Korean Meteorological Society 42(2): 129-151. 
Badlan et al., The role of deep flaming in violent pyroconvection

Lindsey, D. T. and M. Fromm (2008). Evidence of the cloud lifetime effect from wildfire-induced thunderstorms. Geophysical Research Letters 35(22): 1-5.

Luderer, G., J. Trentmann and M. O. Andreae (2009). A new look at the role of fire-released moisture on the dynamics of atmospheric pyro-convection. International Journal of Wildland Fire 18(5): 554-562.

McRae, R., J. Sharples, S. Wilkes and A. Walker (2013). An Australian pyro-tornadogenesis event. Natural Hazards 65(3): 1801-1811.

McRae, R. H. D., J. J. Sharples and M. Fromm (2015). Linking local wildfire dynamics to pyroCb development. Natural Hazards \& Earth System Sciences 15(3): 417-428.

Moeng, C., J. Dudhia, J. Klemp and P. Sullivan (2007). Examining two-way grid nesting for large eddy simulation of the PBL using the WRF model. Monthly Weather Review 135(6): 2295-2311.

Potter, B. E. (2005). The role of released moisture in the atmospheric dynamics associated with wildland fires. International Journal of Wildland Fire 14(1): 77-84.

Sharples, J. J., G. J. Cary, P. Fox-Hughes, S. Mooney, J. P. Evans, M.-S. Fletcher, M. Fromm, P. F. Grierson, R. McRae and P. Baker (2016). Natural hazards in Australia: extreme bushfire. Climatic Change 139: 15.

Sharples, J. J., R. H. D. McRae and S. R. Wilkes (2012). Wind-terrain effects on the propagation of wildfires in rugged terrain: fire channelling. International Journal of Wildland Fire 21(3): 282-296.

Simpson, C., J. Sharples and J. Evans (2014). Resolving vorticity-driven lateral fire spread using the WRFFire coupled atmosphere-fire numerical model. Natural Hazards and Earth System Sciences 14(9): 23592371.

Simpson, C. C., J. J. Sharples, J. P. Evans and M. F. McCabe (2013). Large eddy simulation of atypical wildland fire spread on leeward slopes. International Journal of Wildland Fire 22(5): 599-614.

Skamarock, W. C., J. B. Klemp, J. Dudhia, D. O. Gill, D. M. Barker, M. G. Duda, W. Wang and J. G. Powers (2008). A description of the Advanced Research WRF version 3, Tech Note 475. NCAR.

Teague, B., R. McLeod and S. Pascoe (2010). Final report, 2009 Victorian bushfires Royal Commission. Parliament of Victoria, Melbourne Victoria, Australia.

Thurston, W., K. J. Tory, R. J. Fawcett and J. D. Kepert (2015). Large-eddy simulations of pyro-convection and its sensitivity to environmental conditions. Bushfire and Natural Hazards CRC \& AFAC Conference. Adelaide 2015.

Thurston, W., K. J. Tory, R. J. Fawcett and J. D. Kepert (2016). The effects of turbulent plume dynamics on long-range-spotting. AFAC16. Sydney, Bushire and Natural Hazards CRC, 2016. 